\title{
Research on energy storage technologies for marine current energy systems*
}

\author{
Wen-Jun She ${ }^{\mathrm{a}}$ and Xu-Dong Zhang ${ }^{\mathrm{b}}$ \\ Nanjing University of Science \& Technology, \\ Nanjing, China

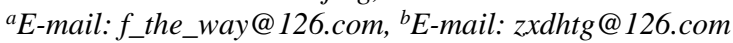

\begin{abstract}
Ocean is a huge renewable energy source, a tremendous amount of electric energy can be extracted from marine currents. However, the electric energy extracted from the marine currents is very volatile due to the swell effect and the periodicity of the tidal phenomenon. Energy storage system can play a crucial role in the marine energy system to improve the power quality and make the marine generation system more reliable. In this paper, different energy storage technologies are introduced and discussed. It is shown that super-capacitor and flywheel are more suitable for compensating short-period power fluctuation due to swell effect while sodium-sulfur batteries and flow batteries are favorable for smoothing the long-period power fluctuation due to the tidal phenomenon. Finally, it is concluded that the hybrid energy storage technology has a great application prospect in the marine current energy system.
\end{abstract}

Keywords: Marine Current Energy; Energy Storage; Power Fluctuation.

\section{Introduction}

Nowadays, more and more renewable energy is needed to replace traditional energy sources to reduce pollution and reduce carbon dioxide emissions. As a kind of ocean energy, marine current energy is very popular because of its high predictability. The main challenge for the application in marine current energy system is power fluctuation phenomenon both on short-time and long-time scales. The energy storage system is considered to be an effective solution, which can smooth power fluctuations and improve the reliability of the system. In this paper, different energy storage technologies are introduced. The ideal application environment varies for each technology due to their particular characteristic. Basic understanding of each energy storage technology and comparisons among them can help to make a better choice for marine current energy application.

\footnotetext{
${ }^{*}$ This work is supported by grant 51506092 of the National Natural Science Foundation.
} 


\section{Battery Energy Storage Technology}

Battery is a normal way to store electricity in the form of chemical energy. The rechargeable battery is one of the most widely used energy storage technologies in industry and daily life. A battery consists of a number of electrochemical cells connected in series or parallel, which produce electricity with a desired voltage from an electrochemical reaction. Each battery cell comprises the cathode (positive electrode), the anode (negative electrode) and the electrolyte which provides the medium for transfer of electrons between the two electrodes. Common batteries are Lead-acid batteries, Nickel-based batteries and Lithiumion batteries, in this paper, we introduce only Sodium-Sulfur batteries and Flow batteries.

\subsection{Sodium-sulfur battery}

A sodium-sulfur (NaS) battery consists of molten sodium and molten sulfur as the two electrodes and beta alumina as the solid electrolyte.

The desirable features of $\mathrm{NaS}$ batteries include relatively high energy densities $(150-300 \mathrm{Wh} / \mathrm{L})$, higher rated capacity, almost zero daily selfdischarge, and high pulse power capability $[1,6]$. The NaS battery has a life span of 2500 cycles at $100 \%$ depth of discharge with a high energy efficient about $89 \%$ [2].

The NaS battery seems to be an effective solution for stabilizing energy output during periods of 3-6 $\mathrm{h}$ in order to smooth the output of a marine generator farm. However the operating environment must be perfectly controlled if this solution is used.

\subsection{Flow battery}

Flow battery is a type of rechargeable battery which stores energy in two soluble redox couples contained in external liquid electrolyte reservoirs. These electrolytes can be pumped from the reservoirs to the cell stack which consists of two electrolyte flow compartments separated by ion selective membranes. Charging and discharging are realized by means of a reversible reductionoxidation reaction between the two electrolyte. Figure 1 illustrates the structure of a flow battery system. 


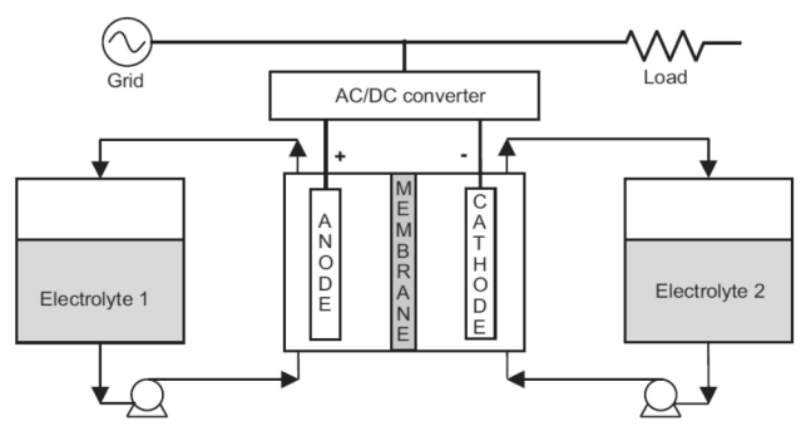

Fig. 1. Flow battery system.

A crucial advantage of flow battery is that the power is independent from its storage capacity [3]. Another significant advantage is the long service life about 10,000 cycles at $75 \%$ depth of discharge. Drawbacks of flow batteries include low performance resulting from non-uniform pressure drops and the reactant mass transfer limitation [4].

Flow batteries can be differently designed for compensating short-time and long-time fluctuations, and they are suitable for smoothing the fluctuation due to tidal phenomenon with energy storage in hours.

\section{Super-Capacitor Energy Storage Technology}

Super-capacitors which contain two conductor electrodes, an electrolyte and a porous membrane separator are also known as electrochemical double-layer capacitors and ultra-capacitors. They work in a similar way as conventional capacitors, but are characterized by a much higher capacitance (kilo farads) in smaller packages [5]. The two electrodes are separated by a very thin porous separator which is immersed in the electrolyte. The electrolyte is either aqueous or organic. By using high-permittivity dielectric and maximizing the electrode surface area with nano materials, super-capacitors are able to store large amount of energy at the electrode surface. Figure 2. shows the structure of one individual super-capacitor cell.

Super-capacitors can be cycled more than 500,000 times and have a service life of 12 years thanks to that the electrodes will not be chemically degraded. The charging and discharging process of super-capacitors are much faster than batteries, costing only seconds. Energy efficiency is high and no heat or hazardous substances are released during operation. However, the daily selfdischarge rate of super-capacitors is high, about $5-40 \%$, and the capital cost is also high, in excess of $6000 \$ / \mathrm{kWh}[6]$. 


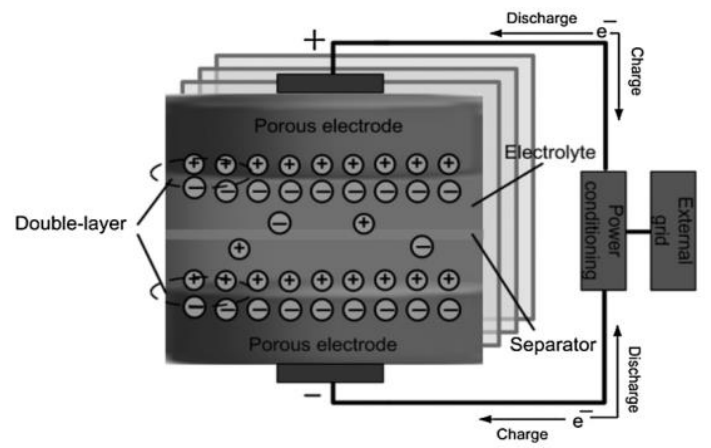

Fig. 2. Super-capacitor system

Based on the characteristics of high cycling capability and high power performance, the super-capacitor technology seems to be one appropriate solution for compensating the short-term in marine current energy storage system.

\section{Flywheel Energy Storage Technology}

A flywheel energy storage (FES) system works through accelerating a rotor (flywheel) to a very high speed and maintaining the energy in the system as rotational energy. When energy is added to the system, the flywheel's rotational speed is increased; extracting energy from the system correspondingly results in an decrease in the speed of the flywheel. A typical FES system (Figure 3), consists of a massive rotating cylinder that is supported on a stator by magnetically levitated bearings. The flywheel system is operated in a vacuum chamber to reduce friction and losses. A motor/generator is connected to the flywheel to interact with the power grid or the renewable energy sources.

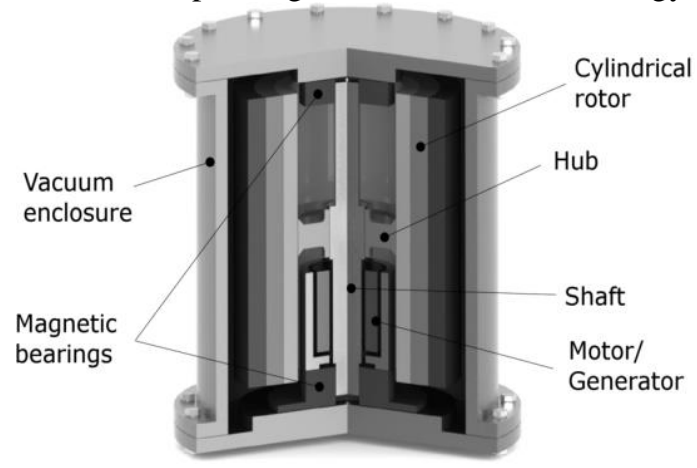

Fig. 3. Typical flywheel structure

There are two kinds of flywheel technologies according to the rotational speed: low speed flywheels (less than 10,000rpm) and high speed flywheels 
(more than 10,000rpm)[7]. The energy density of a typical low speed flywheel with steel rotor is $5 \mathrm{Wh} / \mathrm{kg}$, and the high speed one with composite rotor can achieve a energy density of up to $100 \mathrm{Wh} / \mathrm{kg}$ [8].

FES has some favorable characteristics, including high cyclic ability (over 105 cycles with deep discharge or 20 years' service time), high cycle efficiency (up to $95 \%$ at rated power), relatively high energy density (100 Wh/kg), no depth-of-discharge effects and low maintenance [8,9]. While FES has a high self-discharge rate which is typically over $20 \%$ per hour [10], making it not suitable for long-term applications.

FES seems very appropriate for providing short-term ride-through power or smoothing the power fluctuations on a time scale of several seconds to $15 \mathrm{~min}$, based on these characters discussed above. Therefore, FES can become a very promising candidate to smooth short-term fluctuations related to swell effects in marine current energy storage system.

\section{Conclusion}

With all the characteristics of each energy storage technology discussed above, a conclusion is easily drawn. For long-term energy storage (several hours), batteries are the best candidates for marine current systems. Both $\mathrm{NaS}$ batteries and flow batteries can be used for smoothing long-term (3-6h) power fluctuations due to the tidal phenomenon. While for short-term energy storage (seconds to minutes), super-capacitor and flywheel technologies are most suitable technologies for them being able to smooth short-term power fluctuations due to swell effects. Considering different characteristics of flywheels and super-capacitors in short-term energy storage and $\mathrm{NaS}$ batteries and flow batteries in long-term energy storage, it is very promising to develop hybrid energy storage systems for achieving optimal results in marine current energy applications.

\section{References}

1. Kawakami, Noriko, et al. Development and field experiences of stabilization system using 34MW NAS batteries for a $51 \mathrm{MW}$ wind farm. IEEE International Symposium on Industrial Electronics IEEE, 2010:23712376.

2. Divya, K. C., and J. Østergaard. Battery energy storage technology for power systems-An overview. Electric Power Systems Research 79.4(2009):511-520.

3. Baker, John. New technology and possible advances in energy storage. Energy Policy 36.12(2008):4368-4373. 
4. Mccrabb, H., and S. Snyder. An Electrochemical Etching Process for Flow Battery Structures to Improve Performance and Reduce Manufacturing Cost. ECS Meeting 2014.

5. Vazquez, S., et al. Energy Storage Systems for Transport and Grid Applications. IEEE Transactions on Industrial Electronics 57.12(2011): 3881-3895.

6. Díaz-González, Francisco, et al. A review of energy storage technologies for wind power applications. Renewable \& Sustainable Energy Reviews 16.4(2012): 2154-2171.

7. Cimuca, G. O., et al. Control and Performance Evaluation of a Flywheel Energy-Storage System Associated to a Variable-Speed Wind Generator. Industrial Electronics IEEE Transactions on 53.4(2006): 1074-1085.

8. Hadjipaschalis, Ioannis, A. Poullikkas, and V. Efthimiou. Overview of current and future energy storage technologies for electric power applications. Renewable \& Sustainable Energy Reviews 13.6-7(2009): 1513-1522.

9. Peña-Alzola, R., et al. "Review of flywheel based energy storage systems." International Conference on Power Engineering IEEE, 2011:1-6.

10. Doucette, Reed T., and M. D. Mcculloch. A comparison of high-speed flywheels, batteries, and ultra capacitors on the bases of cost and fuel economy as the energy storage system in a fuel cell based hybrid electric vehicle. Journal of Power Sources 196.3(2011): 1163-1170. 